\title{
Study on Viscoelastic Deformation Monitoring Index of an RCC Gravity Dam in an Alpine Region Using Orthogonal Test Design
}

\author{
Yaoying Huang $\mathbb{D}^{1}$ and Zhiyong Wan $\mathbb{D}^{2}$ \\ ${ }^{1}$ College of Hydraulic \& Environmental Engineering, China Three Gorges University, Yichang 443002, China \\ ${ }^{2}$ State Key Laboratory of Water Resources and Hydropower Engineering Science, Wuhan University, Wuhan 430072, China \\ Correspondence should be addressed to Zhiyong Wan; zhiyongwan@whu.edu.cn
}

Received 15 January 2018; Accepted 26 March 2018; Published 9 May 2018

Academic Editor: Xander Wang

Copyright (c) 2018 Yaoying Huang and Zhiyong Wan. This is an open access article distributed under the Creative Commons Attribution License, which permits unrestricted use, distribution, and reproduction in any medium, provided the original work is properly cited.

\begin{abstract}
The main objective of this study is to present a method of determining viscoelastic deformation monitoring index of a Rollercompacted concrete (RCC) gravity dam in an alpine region. By focusing on a modified deformation monitoring model considering frost heave and back analyzed mechanical parameters of the dam, the working state of viscoelasticity for the dam is illustrated followed by an investigation and designation of adverse load cases using orthogonal test method. Water pressure component is then calculated by finite element method, while temperature, time effect, and frost heave components are obtained through deformation statistical model considering frost heave. The viscoelastic deformation monitoring index is eventually determined by small probability and maximum entropy methods. The results show that (a) with the abnormal probability $1 \%$ the dam deformation monitoring index for small probability and maximum entropy methods is $23.703 \mathrm{~mm}$ and $22.981 \mathrm{~mm}$, respectively; thus the maximum measured displacement of the dam is less than deformation monitoring index, which indicates that the dam is currently in a state of safety operation and (b) the obtained deformation monitoring index using orthogonal test method is more accurate due to the full consideration of more random factors; the method gained from this study will likely be of use to diagnose the working state for those RCC dams in alpine regions.
\end{abstract}

\section{Introduction}

A Roller-compacted concrete (RCC) dam is constructed with the Roller-compacted placement method in thin layers of dry lean concrete, composed of mixed sand aggregate and cement [1]. In recent years, RCC dams have been commonly applied in dam domains because of its low cost, rapid construction, and a better control of heat generation of concrete. However, the safety of RCC dams during operation period is extremely crucial, especially in alpine regions. In order to ensure the safety operation of dams over the long-term service period, it is necessary to monitor the dam working performance by carrying out real-time analysis of monitoring data $[2,3]$. As the deformation monitoring index is a crucial index to evaluate and monitor dam safety, it is of high engineering significance for the safety operation of dams. Generally, the deformation monitoring index is an alarm or extreme value of deformation under possible loads according to the Technical Specification for Concrete Dams Safety Monitoring [4].

The deformation monitoring index of dams may be primarily determined using two approaches. Initially, the deformation monitoring index is obtained through the mining of dam deformation information using mathematical model on the basis of the existing monitoring effect quantity. Prior studies on monitoring index determined by mathematical model have focused on the methods of confidence interval, small probability, and statistical model $[5,6]$ which have been commonly used in numerous projects. However, due to the lack of consideration about spaciousness and fuzziness as well as randomness for multipoint monitoring in these methodologies, in recent years, Lei et al. [7] proposed the early warning index of spatial deformation of high concrete 
dams based on deformation entropy; G. Yang and M. Yang [8] proposed the determination method of multistage warning indicators for the overall deformation of concrete dam regarding fuzziness and randomness; Qin et al. [9] combined comprehensive block displacement with multidimensional confidence region method to diagnose the safety of concrete double-curvature arch dam in Sichuan Province, China. Although it is convenient for engineers to determine deformation monitoring index by these mathematical models, the calculated displacement is the only alarm value or extreme value when the dam has experienced the extreme load case combinations in the long-term monitoring data.

On the other side, the deformation extreme value can also be determined on the basis of the structural numerical techniques of the dam body and its foundation. Numerous scholars have attempted, in terms of finite element numerical techniques, to assemble the adverse loads of dams that may occur during operation period, which makes up for the shortage of the adverse load combination cases of monitoring data series observed by precise instruments. For instance, $\mathrm{Wu}$ et al. [10] proposed that the structural characteristics of RCC dams should be divided into three stages: elasticity, elasticplasticity, and unstable failure. The deformation monitoring index of dams was determined through the introduction of the statistical model [11-14], and the method was successfully applied to Shapai RCC arch dam in Sichuan province, China. Considering the complexity characteristics of RCC structure [15], such as the complex anisotropy, Gu [16] defined the diagnostic index of three-stage safety deformation from the perspective of yield ratio mutation feature of layer surface and foundation plane, and then the theory was successfully applied to Longtan dam project in Guangxi province, China.

Prior studies on monitoring index have focused on adverse load combinations that offer a simple combination by the accumulation of adverse loads rather than forming a full consideration on the actual situations (e.g., loads, boundary conditions, and uncertain parameters). For instance, the Canadian Turkstra combination rule is customarily used in the engineering field, which holds that the maximum effect value of the load combination manifests when a variable load reaches the maximum value in the design benchmark period and the other variable loads are in the form of instantaneous value [10]. The form of load combination is pretty rough with the characteristics of subjective factor; in particular, the running state of dams presents the characteristics of fuzziness and randomness; thus the load combination cases selected are not always representative. Moreover, with the presentation of the complex behavior of dams in alpine regions, only few scientific publications have been published concerning deformation monitoring index of dams in alpine regions. Therefore, a typical combination of adverse case sample is selected using orthogonal test design method [17] so as to determine deformation monitoring index of dams in alpine regions.

In this study, a typical RCC gravity dam in an alpine region is taken as a case, and the typical water retaining dam block is selected as an analysis object. A combination sample of adverse cases is designed using orthogonal test method; the total effect quantity (i.e., deformation) sample is obtained through statistical model and finite element method, and then the viscoelastic deformation monitoring index for the dam in an alpine region is eventually determined based on the small probability and maximum entropy methods.

\section{A Method of Determining Viscoelastic Deformation Monitoring Index for RCC Gravity Dams}

2.1. Orthogonal Test Design. Orthogonal test design, as a highly efficient way capable of dealing with multifactor tests, is commonly adopted to arrange and analyze datasets by means of selecting a reasonable orthogonal table based on levels and factors [17]. In considerable combinations, it is convenient to conduct a test with the method employed to select a representative combination with the characteristics of "uniform dispersion" and "neatly comparable." Simultaneously, it may make the test cases with approaches of different combinations analyzed comprehensively available, which is characterized by less times, high execution efficiency, and convenient operation.

\subsection{Effect Quantities of Adverse Load Combination}

2.2.1. Deformation Statistical Model Considering Frost Heave. In the case of an RCC dam in an alpine region, the dam crest displacement is affected by water pressure, temperature, time effect, and frost heave $[6,18,19]$ when the dam crest has no thermal insulation measures. For this purpose, the modified deformation statistical model for the concrete dams considering frost heave in alpine regions is expressed as follows:

$$
\delta=\delta_{H}+\delta_{T}+\delta_{\theta}+H\left(\lambda_{0}-\lambda\right) \delta_{D}
$$

where $\delta_{H}$ represents the displacement caused by dam body and its foundation deformation under the action of a water load; $\delta_{T}$ represents the displacement caused by the temperature change of dam body concrete and dam foundation rock; $\delta_{\theta}$ denotes the time effect (time-dependent) displacement which is employed to represent the creep of dam concrete and bedrock, as well as the plastic joint deformation; $\delta_{D}$ (i.e., $\left.\delta_{D}=\delta_{D 1}+\delta_{D 2}\right)$ denotes the frost heave deformation of dams in alpine regions, including a periodic term $\delta_{D 1}$ and a hysteresis term $\delta_{D 2}$. The water pressure, temperature, and frost heave are assumed to be elastic components, while the plastic components caused by water pressure, temperature, and frost heave are all included in the time effect component. These components $[6,18]$ can be written as follows:

$$
\begin{aligned}
\delta_{H} & =\sum_{i=0}^{m} a_{i}\left(H^{i}-H_{0}^{i}\right), \\
\delta_{T} & =\sum_{i=1}^{m_{1}}\left[b_{1 i}\left(\sin \frac{2 \pi i t}{365}-\sin \frac{2 \pi i t_{0}}{365}\right)\right. \\
& \left.+b_{2 i}\left(\cos \frac{2 \pi i t}{365}-\cos \frac{2 \pi i t_{0}}{365}\right)\right],
\end{aligned}
$$




$$
\begin{aligned}
\delta_{\theta} & =c_{1}\left(\ln \theta-\ln \theta_{0}\right)+c_{2}\left(e^{-0.1 \theta}-e^{-0.1 \theta_{0}}\right)+c_{3}\left(e^{-0.01 \theta}\right. \\
& \left.-e^{-0.01 \theta_{0}}\right) \\
\delta_{D 1} & =\sum_{i=2,4,8, \ldots}^{m}\left[d_{i 1} I \sin \left(\frac{2 \pi i\left(x-x_{0}\right)}{365}\right)\right. \\
& \left.+d_{i 2} I \cos \left(\frac{2 \pi i\left(x-x_{0}\right)}{365}\right)\right], \\
\delta_{D 2} & =d_{1} I_{20-10}+d_{2} I_{20-20}+d_{3} I_{20-30}+d_{4} I_{30-10} \\
& +d_{5} I_{30-20}+d_{6} I_{30-30},
\end{aligned}
$$

where $a_{i}$ is the water pressure component regression coefficient; $m=3$ for a gravity dam and $m=4$ for an arch dam; $H$ is the water depth on the monitoring day and $H_{0}$ is the water depth of the beginning day; and $b_{1 i}$ and $b_{2 i}$ are temperature component regression coefficients. $m_{1}=1$ or 2 corresponds to a year and half-year cycle, respectively, and $c_{1}$, $c_{2}$, and $c_{3}$ are time effect component regression coefficients. $t$ denotes the cumulative days from the beginning day to the monitoring day, $t_{0}$ denotes the days from the beginning day to the calculated day; $\theta$ denotes the number of days from the beginning day to the monitoring day divided by $100 ; \theta_{0}$ denotes the number of days from the beginning day to the calculated day divided by 100 .

$I$ represents the frost heave factor to distinguish the periodic function in the same model; $x$ represents the number of days from the beginning day to the monitoring day; $x_{0}$ represents the number of days from the beginning day of the analyzed monitoring series to the beginning day of the negative temperature in the same year; $d_{i 1}$ and $d_{i 2}$ are the frost heave component periodic regression coefficients; $d_{1}, d_{2}, \ldots$, and $d_{i}(i=1-6)$ are the frost heave component hysteresis regression coefficients; and $I_{i-j}$ represents temperature hysteresis factor, $i$ denotes the effect of time on temperature hysteresis, and $j$ denotes the number of days at the average temperature before the hysteresis time is affected. Generally, as a unit of weeks, days, or months, the hysteresis days are determined by the measured temperature and hysteresis temperature of dams.

Additionally, $H\left(\lambda_{0}-\lambda\right)$ in (1), with respect to a definite step function, is defined by

$$
\begin{aligned}
& H\left(\lambda_{0}-\lambda\right) \\
& = \begin{cases}0 & \lambda>\lambda_{0} \text { (without considering frost heave) } \\
1 & \lambda<\lambda_{0} \text { (considering frost heave) },\end{cases}
\end{aligned}
$$

in which $\lambda_{0}=0^{\circ} \mathrm{C}$ is the reference temperature of the concrete, $\lambda$ denotes the concrete temperature, and the function "differential" is a Dirac $\delta$ function due to a jump when $\lambda=\lambda_{0}$; thus, $H\left(\lambda_{0}-\lambda\right)$ is referred to as the unit step function.

2.2.2. Effect Quantities. The basic loads consist of water pressure, uplift pressure, sediment pressure, and other loads regarding the permanent cases during the operation period of dams. Some analysis is conducted by selecting and combining these loads which have a strong influence on structure deformation. Due to the complexity of load combination under adverse cases, in this study, the water pressure and uplift pressure are recognized as the investigated loads, and then the orthogonal test method, according to the range of loads and levels as well as factors, is introduced to assemble loads under adverse cases. Combined with (1), together with finite element numerical techniques, it is feasible to obtain total effect quantity samples.

To be specific, effect quantities consist of water pressure component, temperature component, time effect component, and frost heave component in this study. Water pressure component is calculated using the finite element method, and the transversely isotropic mechanical parameters in the finite element model are obtained from inversion; while the temperature component is calculated through statistical model expression form, as shown in (3), time effect and frost heave components are also calculated by statistical model expressions, as shown in (4) and (5)-(6), respectively.

\subsection{Deformation Monitoring Index of Dams}

(1) Small Probability Method. Effect quantities under each adverse load combination are obtained through the 3D finite element method and deformation statistical model of an RCC dam; thus the sample space is developed; moreover, the Kolmogorov-Smirnov (K-S) distribution test method is utilized to diagnose the probability density function $f\left(E^{\prime}\right)$ on the basis of the eigenvalues (i.e., mean and standard deviation) of samples. Here $E_{m}^{\prime}$ is considered as the deformation monitoring index value; the running state of a dam will be abnormal provided that $E^{\prime}$ (measured data) is greater than $E_{m}^{\prime}$ (monitoring index); the abnormal probability of dam deformation can be given by

$$
P\left(E^{\prime}>E_{m}^{\prime}\right)=P_{\alpha}=\int_{E_{m}^{\prime}}^{\infty} f\left(E^{\prime}\right) d E^{\prime}
$$

As the abnormality of a dam is regarded as a small probability event, the abnormal probability $\left(P_{\alpha}\right)$ is conventionally determined by the project grade or rank; thus the deformation monitoring index is written as $E_{m}^{\prime}=F^{-1}\left(\bar{E}^{\prime}, \sigma_{E}, P_{\alpha}, \ldots\right)$, where $\bar{E}^{\prime}, \sigma_{E}$ are mean and standard deviation of samples, respectively.

(2) Maximum Entropy Method. The maximum entropy method is able to be adopted when the distribution function for the actual monitoring effect quantities can not fully conform to the classical distribution function. There is no need to assume the distribution function type of samples in advance; the probability density function with higher precision can be obtained directly based on the numerical eigenvalues of samples [20]. The calculation steps are as follows.

Step 1. According to the principle of maximum entropy, when the probability distribution reaches the minimum deviation under the given constraint condition of sample information, 
the entropy $H(x)$ will reach the maximum. The objective function and constraints are written as

$$
\begin{aligned}
\max & H(x)=-\int_{R} f(x) \ln f(x) d x \\
\text { s.t } & \int_{R} f(x) d x=1 \\
& \int_{R} x^{i} f(x) d x=u_{i} \quad(i=0,1,2, \ldots, n) .
\end{aligned}
$$

Additionally,

$$
\mu_{i}=\sum_{k=1}^{N} \frac{x_{k}^{i}}{N}
$$

where $x_{k}$ denotes the $k$-th sample value; $N$ represents sample size; $R$ is the domain of integration and generally it can be approximated as $[E-5 \sigma, E+5 \sigma] ; E$ and $\sigma$ are sample mean value and standard deviation, respectively; $\mu_{0}=1 ; \mu_{i}(i=$ $1,2, \ldots, n)$ is $i$-th origin moment; $n$ is the order of origin moment.

Step 2. According to a set of sample information $x=$ $\left\{x_{1}, x_{2}, \ldots, x_{N}\right\}$, the origin moment of displacement sample is calculated, and the Lagrange multiplier method is employed to solve the maximum value of the entropy $H(x)$. The maximum entropy probability density function is, therefore, expressed as

$$
f(x)=\exp \left(\lambda_{0}+\sum_{i=1}^{n} \lambda_{i} x^{i}\right),
$$

where $\lambda_{0}$ and $\lambda_{i}(i=1,2, \ldots, n)$ represent Lagrange multiplier coefficients.

Hence, according to (10a) and (10b) and (12), the following equation can be obtained.

$$
\begin{aligned}
& \int_{R} x^{i} f(x) d x=\int_{R} x^{i} \exp \left(\lambda_{0}+\sum_{j=1}^{n} \lambda_{j} x^{j}\right) d x \\
&=\frac{\int_{R} x^{i} \exp \left(\sum_{j=1}^{n} \lambda_{j} x^{j}\right) d x}{\int_{R} \exp \left(\sum_{j=1}^{n} \lambda_{j} x^{j}\right) d x}=\mu_{i} \\
&(i=1,2, \ldots, n) .
\end{aligned}
$$

The Lagrange multiplier coefficients of the aforementioned formula are estimated by optimization algorithm.

Step 3. $x_{m}$ is assumed as the deformation monitoring index; the abnormal or dangerous possibility for dams can be described by

$$
P_{\alpha}=\int_{x_{m}}^{+\infty} f(x) d x \quad\left(x>x_{m}\right)
$$

The probability of abnormal behavior for dams is rather low, the abnormal probability $\left(P_{\alpha}\right)$ is commonly regarded as $1 \%$ or $5 \%$ considering structural importance (rank or grade), and then the deformation monitoring index value can be obtained based on the property of the inverse cumulative distribution function.

The flow diagram of implementation for viscoelastic deformation monitoring index of dams is shown as Figure 1.

2.4. Deformation Alarm of RCC Dams. Compared with the measured data $E_{m}$ of the monitoring series, the deformation monitoring index $E_{m}^{\prime}$ can be exploited to diagnose the existing working condition of a dam and offer an early alarm for dam safety; some details are as follows:

(1) The running state of a dam is within normal range provided that the measured data $E_{m}$ is less than $E_{m}^{\prime}$.

(2) The measured data exceeds the normal range provided that the measured data $E_{m}$ is greater than $E_{m}^{\prime}$, and the running state of a dam is abnormal. Thus, it is essential to analyze the reasons and take timely effective engineering measures to control dam deformation until the dam is in normal operation.

\section{Case Study}

\subsection{Description of an RCC Gravity Dam}

(1) General of the Project. A large-scale water conservancy project is situated in the Northwest alpine region of China. Based on many years of data, the annual average temperature is $2.8^{\circ} \mathrm{C}$ at the dam site, with an extreme minimum temperature of $-49.8^{\circ} \mathrm{C}$ and an extreme maximum temperature of $40.1^{\circ} \mathrm{C}$ which have been observed in history. Hence, the environment of region is so harsh that it can be considered as an alpine region. The project has a total reservoir capacity of $2.419 \times 10^{9} \mathrm{~m}^{3}$, and reservoir's normal storage water level and dead water level are $739.00 \mathrm{~m}$ and $680.00 \mathrm{~m}$, respectively. The power station has a total installed capacity of $140 \mathrm{MW}$, and the annual generating capacity reaches $5.19 \times 10^{8} \mathrm{KWh}$.

The project is mainly composed of dam, water diversion system, power plant, and other hydraulic structures. The main dam is composed of a full section Roller-compacted concrete (RCC) gravity dam with a length of $1489 \mathrm{~m}$, a maximum height of $121.50 \mathrm{~m}$, and a dam crest elevation of $745.50 \mathrm{~m}$. Seen from the scale of water conservancy, the safety grade of the project is grade I or larger (1). Layout of the project is shown as Figure 2.

(2) Dam Safety Monitoring Layout. The typical water retaining dam block is selected as the analyzed dam block, as shown in Figure 2. There are three plumb lines and one inverted plumb line. Namely, the monitoring points of PL5-1, PL5-2, and PL53 measured by the plump line are arranged at the elevation of $675.10 \mathrm{~m}, 706.50 \mathrm{~m}$, and $742.70 \mathrm{~m}$, respectively, whereas IP5 is measured by an inverted plumb line in the dam foundation anchored at the elevation of $586.30 \mathrm{~m}$, as shown in Figure 3. 


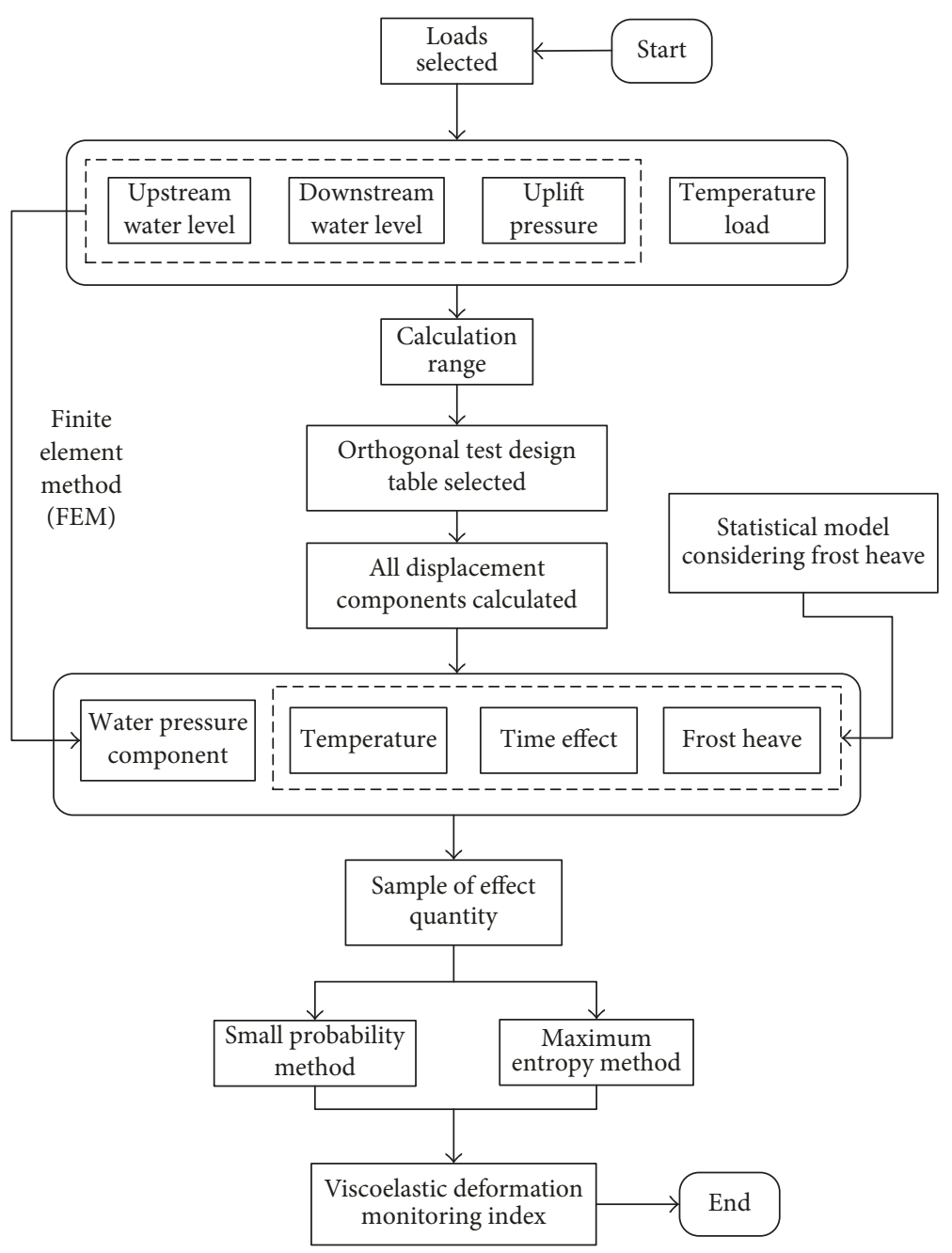

FIGURE 1: Flow diagram of implementation for viscoelastic deformation monitoring index.

\subsection{Analysis and Demonstration of Viscoelastic Deformation}

(1) Quantitative Analysis of Dam Deformation. In view of the typical representation of dam crest monitoring point, the PL5-3 monitoring point of the dam crest is selected as a research object. It can be seen from the measured temperature and the simulation results of dam crest temperature field that large range of negative temperature area appears in the vicinity of dam crest during the period from December 10th to April 25th of the following year. Therefore, it is essential to consider the frost heave deformation of dam crest. The deformation statistical model considering frost heave is established by (1). The fitted data calculated by stepwise regression analysis method is compared with the measured data, as shown in Figure 4. The results show that the measured displacement is in good agreement with the fitted ones, and the complex correlation coefficient is around 0.974 . The separated water pressure component, temperature component, time effect component, and frost heave component (for the initial measured value) are shown in Figure 5. It can be seen from the figure that the frost heave component presents fluctuation, the water pressure component is highly correlated with the change trend of the reservoir water level, and the time effect component tends to be stable in the later stages.

(2) Transversely Isotropic Mechanical Parameters. According to the laboratory test data of the roller compacted concrete (RCC) gravity dam in an alpine region, the elastic modulus of the dam is $31.5-38.0 \mathrm{GPa}$, and the average value of elastic modulus is $34.8 \mathrm{GPa}$. Since the RCC dam is vibrated and compacted with layering by the vibrating grindstone, the RCC is commonly perceived as the transversely isotropic material.

On the basis of the water pressure component separated by the deformation statistical model considering frost heave, the physical and mechanical parameters of the dam and its foundation are back analyzed by uniform design method, BP neural network, and finite element method [21]. Namely, the horizontal equivalent elastic modulus of dam is $39.00 \mathrm{GPa}$; the vertical equivalent elastic modulus of dam is $26.85 \mathrm{GPa}$; the vertical equivalent shear modulus of dam is $16.21 \mathrm{GPa}$; the equivalent deformation modulus of dam foundation is $36.16 \mathrm{GPa}$. 


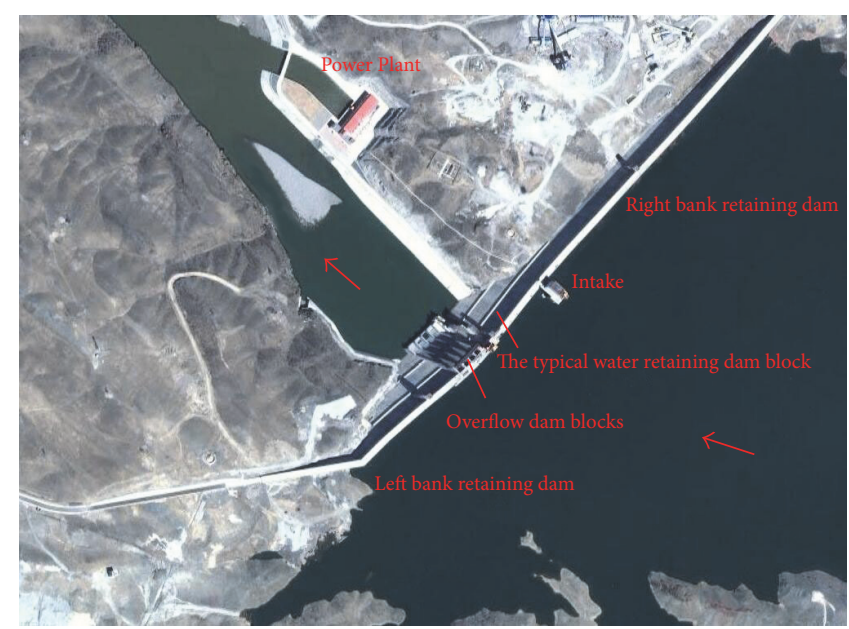

FIGURE 2: Layout of an RCC gravity dam project.

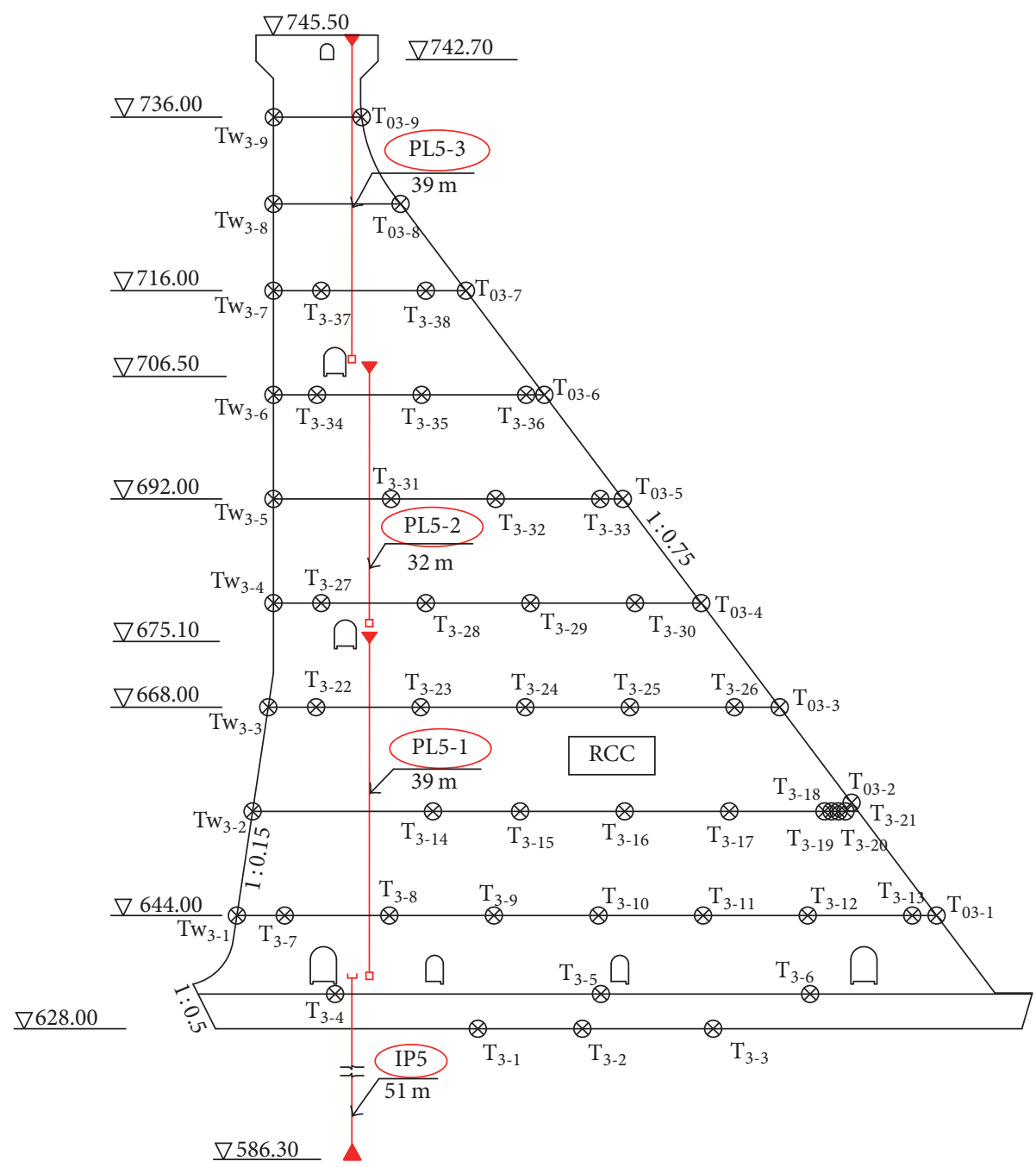

FIGURE 3: Cross-sectional monitoring layout of the typical water retaining dam block (elevation: $\mathrm{m}$ ). 


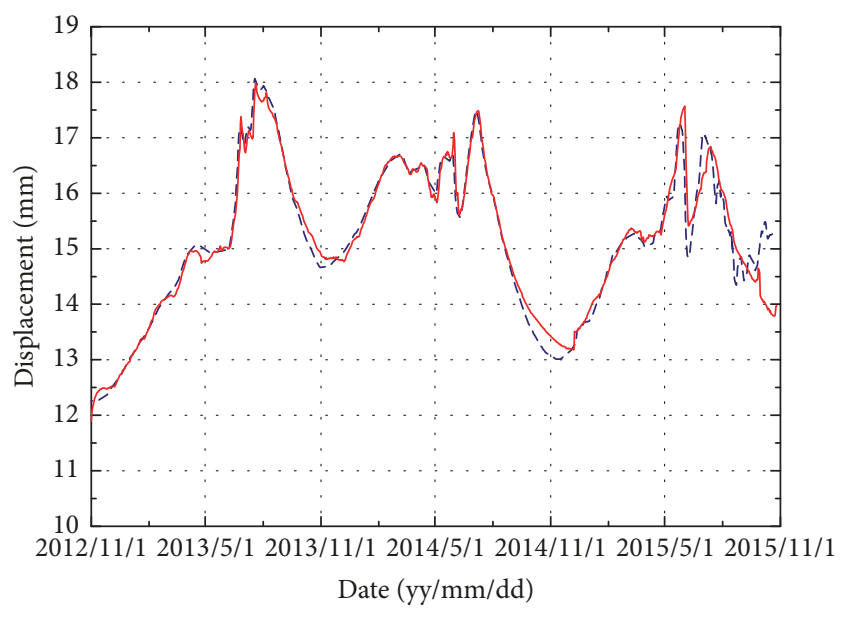

- - Measured data

Fitted data

Figure 4: Comparison between the measured and the fitted displacement of monitoring point for dam crest.

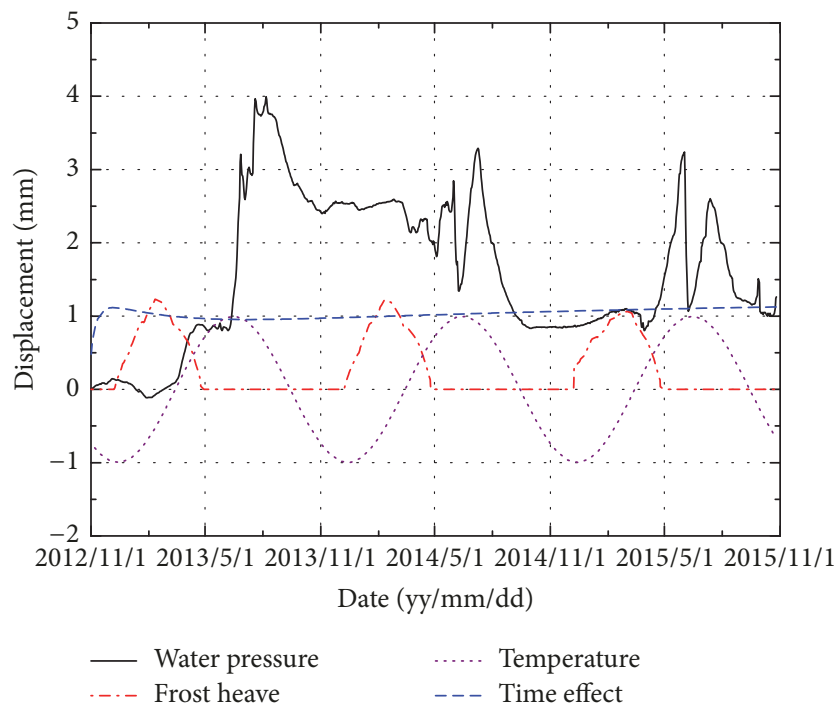

Figure 5: The separated displacement components of monitoring point for dam crest.

There are several discrepancies between the parameters obtained by the inversion and the design parameters. The maximum difference is the horizontal equivalent elastic modulus, and the inversion value is 1.12 times of the designed value; the ratio of horizontal equivalent elastic modulus to vertical equivalent elastic modulus is 1.45 , which is in accordance with the general variation law of RCC (i.e., 1-2).

(3) Demonstration on Working Performance of This RCC Gravity Dam. The viscoelastic deformation of concrete dams not only can embody time-dependent factor but also can present elastic and viscous deformation, which has a crucial scientific significance in the engineering field. From the aforementioned analysis of the established deformation statistical model, we can see that the time effect component of the dam tends to be stable in the later stages; meanwhile, the transversely isotropic parameters of the RCC obtained by the inversion are greater than the design values. To sum up, it can be concluded that the RCC gravity dam is currently in a state of viscoelasticity. Therefore, the viscoelastic deformation monitoring index of the dam is mainly determined during operation period in the following paper.

3.3. Selection of Adverse Load Combination. Prior to selecting adverse cases, the factor having a strong influence or greater variability on a dam is considered as a random variable. According to actual engineering, with the potential impact of the temperature on RCC in alpine regions, the running state of a dam is affected by hydrostatic pressure along upstream and downstream of dams. Furthermore, stability and strength of the dam will be unfavorable if the uplift pressure is too large. Thus the upstream and downstream water level, temperature load, and uplift pressure are perceived as the main influencing factors. The water pressure component is calculated by the inversion results of parameters; the temperature component is calculated by the quasi-stable temperature field and statistical model. In addition, there is no available measured data about the uplift pressure; thus the reduction coefficient of uplift pressure is only analyzed herein.

\section{(1) Determining the Scope of Influencing Factors}

(i) Reservoir Water Level. For the analysis of the dam measured data, it can be seen that the reservoir water level is above normal reservoir water level $(739.00 \mathrm{~m})$ from July 19, 2013, to August 22, 2013, the maximum water level has reached $739.50 \mathrm{~m}$ during operation period, and the high water level in other periods is below $739.00 \mathrm{~m}$. The extreme values of adverse deformation may not occur in history since the monitoring series is rather short; thus in order to reflect the impact of water load upon dam deformation at different high water levels, the range of reservoir water level is selected as $737.50-743.50 \mathrm{~m}$, whereas the range of downstream water level is selected as $641.02-646.18 \mathrm{~m}$.

(ii) Temperature Load. In the absence of load design data of the dam, the maximum rise and drop in temperature are determined by the simulation results of quasi-stable temperature field. The range of temperature load for the monitoring point of dam crest is $-10.1-18.4^{\circ} \mathrm{C}$.

(iii) Uplift Pressure Load. Due to lack of measured data, the effect of uplift pressure reduction coefficient upon dam deformation is analyzed herein. The range of reduction coefficient is $0.19-0.31$.

(2) Orthogonal Design Table. Till now, the maximum water level of the dam during operation period is basically close to normal storage water level $(739.00 \mathrm{~m})$, the sample data of the monitoring is insufficient, and the extreme value of monitoring series may not contain the adverse cases that occurred in history. Therefore, in order to ensure the accuracy of the deformation monitoring index, a combination of adverse cases is obtained comprehensively using orthogonal test design method. 


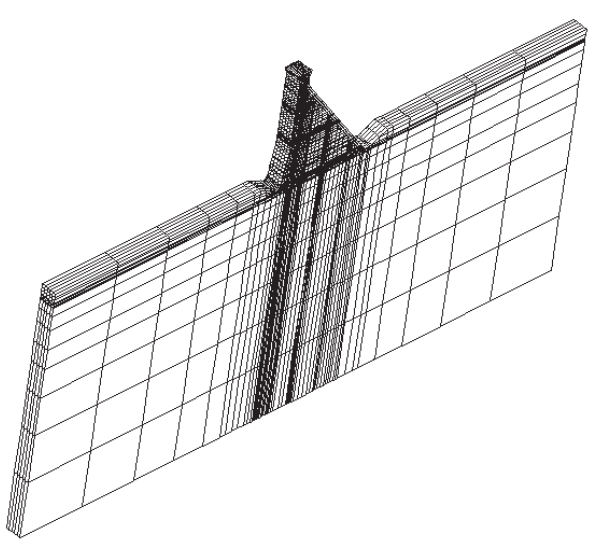

(a)

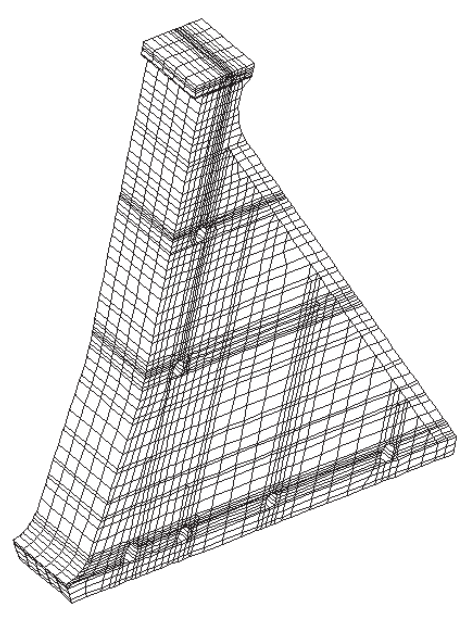

(b)

FIGURE 6: 3D finite element model of the typical water retaining dam block. (a) Dam-foundation model and (b) Dam body model.

It is seen from the analysis that the upstream reservoir water level, the downstream water level, the temperature load, and the uplift pressure are considered as the main loads that affect dam deformation. Therefore, according to the orthogonal test design table, four influential factors of upstream water level, downstream level, temperature load, and reduction coefficient of uplift pressure are selected, and four levels are set for each factor, as shown in Table 1 .

The orthogonal table $\mathrm{L}_{16}\left(4^{5}\right)$ is selected to constitute 16 sets of load combinations including 4 factors and 4 levels, as shown in Table 2.

As presented in Table 2, the columns of A, B, C, and D in the orthogonal table are used because of four factors, and A, B, C, and D represent upstream water level, downstream water level, temperature load, and uplift pressure reduction coefficient, respectively. Taking number 5 as an example, the calculated cases primarily include A-2, B-1, C-2, and D-3, where A-2 represents the reservoir water level $739.50 \mathrm{~m}, \mathrm{~B}-1$ represents the downstream water level $641.02 \mathrm{~m}, \mathrm{C}-2$ represents the temperature load $-0.6^{\circ} \mathrm{C}, \mathrm{D}-3$ represents the uplift pressure reduction coefficient 0.27 , and other similar cases can be obtained by analogy.

\subsection{Calculation and Analysis of Adverse Load Combination Samples}

(1) Computation Model. A 3D finite element model is established to calculate the water pressure component using the mechanical parameters of RCC dam body and its foundation. The other components (e.g., temperature, time effect, and frost heave) are calculated by the expressions of statistical model, as shown in (3)-(7). Remarkably, the finite element model information of dam and its foundation is as follows.

The calculation range of the model is twice the height of dam along the upstream and downstream as well as the depth of dam foundation. The positive direction of $x$-axis is towards downstream, and $z$-axis is directed from left bank to right bank which is perpendicular to the direction of water flow. The positive direction of $y$-axis is upward. The upstream and downstream surfaces have their horizontal displacements constrained to zero, respectively; the left and right banks have their horizontal displacements constrained to zero, respectively; the bottom of the dam foundation has its horizontal and vertical displacements constrained to zero.

The mesh division of dam and its foundation is conducted using hexahedral eight-node isoparametric element and a small amount of degraded tetrahedron or pentahedral elements. The monitoring points are arranged on the nodes as soon as possible when the mesh is divided. Simultaneously, the mesh generation in the vicinity of gallery is conducted using the local mesh refinement method. The total number of element in the finite element model is 13620, with the dam body containing 10540 elements, and the number of nodes is 17274. The finite element model of the typical water retaining dam block is shown in Figure 6.

(2) Further Analysis. As shown in Figure 5, the change of each month is basically identical due to the periodic variation of the temperature component and frost heave component, so the selected displacements depend on temperature load. Namely, the occurrence time of temperature load is determined by the quasi-stable temperature field, and then the corresponding value (i.e., temperature component and frost heave component) of deformation monitoring statistical model is determined. Moreover, all components are determined from the relative values between the calculated water level and the initial water level (initial value measured on November 1,2012); the convergence value is considered as the time effect value since the time effect component tends to be stable. The adverse load combination and all components are shown in Table 3 . The calculated total displacement of dam crest is shown in Table 4.

The following conclusions can be obtained from Table 4 .

(i) When the high water level is at elevation of $737.50 \mathrm{~m}$, $739.50 \mathrm{~m}, 741.50 \mathrm{~m}$, and $743.50 \mathrm{~m}$, with the changes of temperature load and uplift pressure, the deformation monitoring 
TABLE 1: Factors and levels diagram of adverse loads.

\begin{tabular}{lcccc}
\hline \multirow{2}{*}{ Levels } & \multicolumn{3}{c}{ Factors } \\
& Upstream water level $(\mathrm{m})$ & Downstream water level $(\mathrm{m})$ & Temperature load $\left({ }^{\circ} \mathrm{C}\right)$ & Reduction coefficient of uplift pressure \\
\hline 1 & 737.50 & 641.02 & -10.1 & 0.19 \\
2 & 739.50 & 642.74 & -0.6 & 0.23 \\
3 & 741.50 & 644.46 & 8.9 & 0.27 \\
4 & 743.50 & 646.18 & 18.4 & 0.31 \\
\hline
\end{tabular}

TABLE 2: The orthogonal design table $\mathrm{L}_{16}\left(4^{5}\right)$.

\begin{tabular}{llllll}
\hline Number & A & B & C & D & E \\
\hline 1 & 1 & 1 & 1 & 1 & 1 \\
2 & 1 & 2 & 2 & 2 & 2 \\
3 & 1 & 3 & 3 & 3 & 3 \\
4 & 1 & 4 & 4 & 4 & 4 \\
5 & 2 & 1 & 2 & 3 & 4 \\
6 & 2 & 2 & 1 & 4 & 3 \\
7 & 2 & 3 & 4 & 1 & 2 \\
8 & 2 & 4 & 3 & 2 & 1 \\
9 & 3 & 1 & 3 & 4 & 2 \\
10 & 3 & 2 & 4 & 3 & 1 \\
11 & 3 & 3 & 1 & 2 & 4 \\
12 & 3 & 4 & 2 & 1 & 3 \\
13 & 4 & 1 & 4 & 2 & 3 \\
14 & 4 & 2 & 3 & 1 & 4 \\
15 & 4 & 3 & 2 & 4 & 1 \\
16 & 4 & 4 & 1 & 3 & 2 \\
\hline
\end{tabular}

index of dam crest is also unidentical. The mean values of the four cases are $19.39 \mathrm{~mm}, 20.08 \mathrm{~mm}, 21.42 \mathrm{~mm}$, and $22.21 \mathrm{~mm}$, respectively. From the analysis of the measured data, such as water level of $737.58 \mathrm{~m}$ that appeared on July 7, 2013 when it was in hot season, the monitoring displacement value of $17.20 \mathrm{~mm}$ which is less than the deformation monitoring index of $19.39 \mathrm{~mm}$, and the actual operation of the project shows that the dam is in a state of safety operation. Also high water level of $739.5 \mathrm{~m}$ appeared on August 6, 2013; the actual monitoring value of $17.89 \mathrm{~mm}$ is less than deformation monitoring index of $20.08 \mathrm{~mm}$; thus it is demonstrated that the dam does not present adverse situation. To summarize, the dam is currently in a safe condition.

(ii) As presented in Table 4, the water level of $737.50 \mathrm{~m}$ and $739.50 \mathrm{~m}$ is subordinate to high water level of the prototype monitoring series, and the deformation monitoring index based on the monitoring series of PL5-3 monitoring point of dam crest is around $19.00 \mathrm{~mm}$ [21], while the deformation monitoring index based on statistical model and finite element method is around $18.60-20.64 \mathrm{~mm}$. It is shown that the deformation monitoring index calculated by statistical model and finite element method is close to the deformation monitoring index based on the monitoring series. In addition, the determined monitoring index based on the orthogonal test design method has been taken thoroughly into account the adverse load combination cases of the dam during operation period, which is considered to be more representative and accurate.

3.5. Deformation Monitoring Index. Based on the total displacement sample of 16 sets of adverse load combination cases (Table 4), according to the principles described in Section 2.3 , the small probability method and the maximum entropy method are employed to determine the deformation monitoring index of an RCC dam in this alpine region.

(1) Small Probability Method. The K-S test method shows that the relationship between the maximum theoretical empirical difference $\left(D_{n}\right)$ and critical value $\left(D_{n 1 \%}\right.$ or $\left.D_{n 5 \%}\right)$ corresponding to the assumed abnormal probability is $\max D_{n}=$ $0.1058<D_{n 1 \%}=0.2500$ and $\max D_{n}=0.1058<D_{n 5 \%}=$ 0.2130 , respectively, indicating that the displacement distribution of the monitoring point at dam crest satisfies normal distribution, namely, $\delta \sim N\left(\delta_{1}, \sigma_{1}\right)$; thus the characteristic parameters (i.e., mean $\delta_{1}$ and standard deviation $\sigma_{1}$ ) of this distribution are $\delta_{1}=20.7744$ and $\sigma_{1}=1.2589$, respectively.

When the measured value $\delta$ is greater than $x_{m}$ (i.e., deformation monitoring index), the abnormal probability $\left(P_{\alpha}\right)$ of dam deformation is presented as follows:

$$
F\left(\delta>x_{m}\right)=P_{\alpha}=\int_{x_{m}}^{+\infty} \frac{\exp \left[-\left(\delta-\delta_{1}\right)^{2} / 2 \sigma_{1}^{2}\right]}{\sqrt{2 \pi} \sigma_{1}} d \delta .
$$

It is seen from the statistical principle and structural importance (rank or grade) that empirical analysis shows that the event is impossible to occur when the abnormal probability $\left(P_{\alpha}\right)$ is assumed to be small. Resuming the abnormal probability $1 \%$ or $5 \%$, the deformation monitoring index of dam crest is $23.703 \mathrm{~mm}$ and $22.845 \mathrm{~mm}$, respectively.

(2) Maximum Entropy Method. According to the total displacement sample series in Table 4, the probability density function of the sample can be obtained using the maximum entropy method. To begin with, the origin moment $\mu_{i}(i=$ $1,2,3,4)$ of sample is calculated, and then (13) is transformed into a system of nonlinear equations; thus $\lambda_{i}(i=1,2,3,4)$ is obtained by the optimization of Newton iterative method, and $\lambda_{0}$ is determined by (10a) and (12). In the course of calculation, as the order of origin moment of sample is larger in Table 4 , the sample data $x$ of monitoring series is transformed into the form of $(x-\mu) / \sigma$ considering the calculation efficiency and precision and $\mu$ and $\sigma$ are the mean and standard deviation of sample, respectively. The coefficients and eigenvalues of maximum entropy probability function are shown in Table 5. 
TABLE 3: The adverse load combinations and components.

\begin{tabular}{|c|c|c|c|c|c|c|c|c|}
\hline Number & $A(m)$ & $\mathrm{B}(\mathrm{m})$ & $\mathrm{C}\left({ }^{\circ} \mathrm{C}\right)$ & $\mathrm{D}$ & $\begin{array}{c}\text { Water pressure } \\
\text { component }(\mathrm{mm})\end{array}$ & $\begin{array}{c}\text { Temperature } \\
\text { component }(\mathrm{mm})\end{array}$ & $\begin{array}{c}\text { Time effect } \\
\text { component }(\mathrm{mm})\end{array}$ & $\begin{array}{c}\text { Frost heave } \\
\text { component }(\mathrm{mm})\end{array}$ \\
\hline 1 & 737.50 & 641.02 & -10.1 & 0.19 & 5.34 & 0.26 & 0.61 & 1.21 \\
\hline 2 & 737.50 & 642.74 & -0.6 & 0.23 & 5.37 & 0.14 & 0.61 & 0.22 \\
\hline 3 & 737.50 & 644.46 & 8.9 & 0.27 & 5.40 & 1.73 & 0.61 & 0.00 \\
\hline 4 & 737.50 & 646.18 & 18.4 & 0.31 & 5.43 & 0.99 & 0.61 & 0.00 \\
\hline 5 & 739.50 & 641.02 & -0.6 & 0.27 & 6.15 & 0.14 & 0.57 & 0.22 \\
\hline 6 & 739.50 & 642.74 & -10.1 & 0.31 & 6.18 & 0.26 & 0.57 & 1.21 \\
\hline 7 & 739.50 & 644.46 & 18.4 & 0.19 & 6.05 & 0.99 & 0.57 & 0.00 \\
\hline 8 & 739.50 & 646.18 & 8.9 & 0.23 & 6.08 & 1.73 & 0.57 & 0.00 \\
\hline 9 & 741.50 & 641.02 & 8.9 & 0.31 & 6.97 & 1.73 & 1.13 & 0.00 \\
\hline 10 & 741.50 & 642.74 & 18.4 & 0.27 & 6.92 & 0.99 & 1.13 & 0.00 \\
\hline 11 & 741.50 & 644.46 & -10.1 & 0.23 & 6.86 & 0.26 & 1.13 & 1.21 \\
\hline 12 & 741.50 & 646.18 & -0.6 & 0.19 & 6.81 & 0.14 & 1.13 & 0.22 \\
\hline 13 & 743.50 & 641.02 & 18.4 & 0.23 & 7.67 & 0.99 & 1.13 & 0.00 \\
\hline 14 & 743.50 & 642.74 & 8.9 & 0.19 & 7.61 & 1.73 & 1.13 & 0.00 \\
\hline 15 & 743.50 & 644.46 & -0.6 & 0.31 & 7.74 & 0.14 & 1.13 & 0.22 \\
\hline 16 & 743.50 & 646.18 & -10.1 & 0.27 & 7.69 & 0.26 & 1.13 & 1.21 \\
\hline
\end{tabular}

Note. A, B, C, and D represent the upstream water level, downstream water level, temperature load, and uplift pressure reduction coefficient, respectively, which is the same as the symbols of Table 4 . The values of all components are relative to the value of November 1, 2012. The initial water level is $714.46 \mathrm{~m}$, the downstream water level is $642.10 \mathrm{~m}$, and the initial total displacement is $12.26 \mathrm{~mm}$.

TABLE 4: The total displacement of dam crest under different cases.

\begin{tabular}{lccccc}
\hline Number & $\mathrm{A}(\mathrm{m})$ & $\mathrm{B}(\mathrm{m})$ & $\mathrm{C}\left({ }^{\circ} \mathrm{C}\right)$ & $\mathrm{D}$ & Total displacement $(\mathrm{mm})$ \\
\hline 1 & 737.50 & 641.02 & -10.1 & 0.19 & 19.68 \\
2 & 737.50 & 642.74 & -0.6 & 0.23 & 0.27 \\
3 & 737.50 & 644.46 & 8.9 & 0.31 & 20.00 \\
4 & 737.50 & 646.18 & 18.4 & 0.27 & 19.29 \\
5 & 739.50 & 641.02 & -0.6 & 0.31 & 20.48 \\
6 & 739.50 & 642.74 & -10.1 & 0.19 & 19.87 \\
7 & 739.50 & 644.46 & 18.4 & 0.23 & 20.64 \\
8 & 739.50 & 646.18 & 8.9 & 0.31 & 22.09 \\
9 & 741.50 & 641.02 & 8.9 & 0.27 & 21.30 \\
10 & 741.50 & 642.74 & 18.4 & 0.23 & 21.72 \\
11 & 741.50 & 644.46 & -10.1 & 0.19 & 20.56 \\
12 & 741.50 & 646.18 & -0.6 & 0.23 & 22.05 \\
13 & 743.50 & 641.02 & 18.4 & 0.19 & 22.73 \\
14 & 743.50 & 642.74 & 8.9 & 0.31 & 21.49 \\
15 & 743.50 & 644.46 & -0.6 & 0.27 & 22.55 \\
\hline
\end{tabular}

TABLE 5: List of numerical eigenvalues and function coefficients.

\begin{tabular}{lcccc}
\hline $\begin{array}{l}\text { Observation } \\
\text { point number }\end{array}$ & Eigenvalues & Results & Coefficients & Results \\
\hline & $\mu_{0}$ & 1.0000 & $\lambda_{0}$ & -1.5726538 \\
PL5-3 & $\mu_{1}$ & $-6.25 e-04$ & $\lambda_{1}$ & $\lambda_{2}$ \\
& $\mu_{2}$ & 0.9385 & $\lambda_{3}$ & -0.0182553 \\
& $\mu_{3}$ & -0.0122 & $\lambda_{4}$ & -0.4863553 \\
\hline
\end{tabular}


TABLE 6: List of deformation monitoring indexes (Unit: $\mathrm{mm}$ ).

\begin{tabular}{lcccccc}
\hline Observation & \multicolumn{2}{c}{ Eigenvalues } & \multicolumn{2}{c}{ Small probability method } & \multicolumn{2}{c}{ Maximum entropy method } \\
point number & $\delta_{1}(\mu)$ & $\sigma_{1}(\sigma)$ & $P_{\alpha}=1 \%$ & $P_{\alpha}=5 \%$ & $P_{\alpha}=1 \%$ & $P_{\alpha}=5 \%$ \\
\hline PL5-3 & 20.7744 & 1.2589 & 23.703 & 22.845 & 22.981 & 22.671 \\
\hline
\end{tabular}

The maximum entropy probability density function of displacement for dam crest is written as follows:

$$
\begin{aligned}
& f(x)=\exp \left[-1.5726538+\frac{0.0182553(x-\mu)}{\sigma}\right. \\
& +1.1987995\left(\frac{x-\mu}{\sigma}\right)^{2}-0.0109235\left(\frac{x-\mu}{\sigma}\right)^{3} \\
& \left.-0.4863553\left(\frac{x-\mu}{\sigma}\right)^{4}\right]
\end{aligned}
$$

It can be assumed that the abnormal probability is $1 \%$ or $5 \%$ by focusing on the importance of engineering (rank or grade). Considering (14), the deformation monitoring index of dam crest is $22.981 \mathrm{~mm}$ and $22.671 \mathrm{~mm}$, respectively.

(3) Comparison Results of Two Methods. As shown in Table 6, the deformation monitoring index of dam crest determined by small probability method is larger, whereas the dam crest deformation monitoring index calculated by maximum entropy method is smaller. For instance, with the abnormal probability of $1 \%$, the dam crest deformation monitoring index based on small probability method is $23.703 \mathrm{~mm}$, while the dam crest deformation monitoring index for maximum entropy method is $22.981 \mathrm{~mm}$.

3.6. Deformation Alarm of an RCC Gravity Dam. The diagnosis of running state for an RCC gravity dam in an alpine region is conducted via the comparison between the deformation monitoring index determined by small probability and maximum entropy method (Table 6) and the measured data (Figure 4). Results show that the current maximum measured displacement of the dam crest is around $18.0 \mathrm{~mm}$ which is less than the deformation monitoring index. Thereby, the dam is currently in a state of safety operation; on the contrary, it is essential to take the countermeasures to control dam deformation until the deformation is less than the security alarm value provided that the actual monitoring value is greater than the deformation monitoring index in Table 6.

\section{Conclusions}

In this study, an RCC gravity dam project is taken as a case; the method of determining viscoelastic deformation monitoring index of RCC dams in alpine regions is proposed. The following conclusions can be drawn from this study:

(1) The modified monitoring model considering frost heave is proposed; an RCC gravity dam in an alpine region during operation period is taken as a case study; it is demonstrated that the dam is in the viscoelastic working state based on the analysis of the time effect component and the inversed mechanical parameters.

(2) The method of determining viscoelastic deformation monitoring index of RCC dams in alpine regions is proposed. Initially, the combination sample of adverse cases is designed using orthogonal test method, and then each displacement component is calculated using the statistical model and the finite element method. Namely, water pressure component is calculated based on finite element method, and the temperature component is calculated through the quasistable temperature field and the statistical model expression; time effect component and frost heave component are both calculated using statistical model expression; thus the total displacement is obtained under different cases; on the basis of this, the viscoelastic deformation monitoring index is determined by small probability and the maximum entropy methods. The results show that, according to the abnormal probability $1 \%$, the dam crest deformation monitoring index is $23.703 \mathrm{~mm}$ for small probability method, whereas the dam crest deformation monitoring index based on maximum entropy method is $22.981 \mathrm{~mm}$.

(3) On the whole, it is pretty reasonable to determine the deformation monitoring index of the RCC dams in alpine regions based on statistical model and finite element method because of a full consideration of adverse load combination during operation period. Furthermore, it is noteworthy that the maximum measured value is less than the deformation monitoring index, indicating that the dam is currently in a state of safety operation.

\section{Conflicts of Interest}

The authors declare that there are no conflicts of interest regarding the publication of this article.

\section{Acknowledgments}

This research is supported by National Natural Science Foundation of China (nos. 51779130 and 51209124).

\section{References}

[1] U. S. Army Corps of Engineers (USACE), Roller-compacted Concrete, Engineering Manual, No. 1110-2-2006, U.S. Army Corps of Engineers, Washington, DC, USA, 1992.

[2] H. Yu, Z. R. Wu, T. F. Bao, and L. Zhang, "Multivariate analysis in dam monitoring data with PCA," Science China Technological Sciences, vol. 53, no. 4, pp. 1088-1097, 2010.

[3] J. Eichenberger, A. Ferrari, and L. Laloui, "Early warning thresholds for partially saturated slopes in volcanic ashes," Computers \& Geosciences, vol. 49, pp. 79-89, 2013. 
[4] Ministry of Water Resources, Technical Specification for Concrete Dams Safety Monitoring, China Water \& Power Press, Beijing, China, 2013.

[5] M. Fanelli, "Automatic observation for dam safety," International Water Power \& Dam Construction, pp. 10-15, 1979.

[6] Z. R. Wu, Safety monitoring theories \& applications of hydraulic structure, Higher Education Press, Beijing, China, 2003.

[7] P. Lei, X. L. Chang, F. Xiao, G. J. Zhang, and H. Z. Su, "Study on early warning index of spatial deformation for high concrete dam," Science China Technological Sciences, vol. 54, no. 6, pp. 1607-1614, 2011.

[8] G. Yang and M. Yang, "Multistage Warning Indicators of Concrete Dam under Influences of Random Factors," Mathematical Problems in Engineering, vol. 2016, Article ID 6581204, 12 pages, 2016.

[9] X. Qin, C. Gu, B. Chen, C. Liu, B. Dai, and Y. Yu, "Multiblock combined diagnosis indexes based on dam block comprehensive displacement of concrete dams," Optik - International Journal for Light and Electron Optics, vol. 129, pp. 172-182, 2017.

[10] Z. R. Wu, C. S. Gu, and X. H. Wu, RCCD safety monitoring theory and its applications, Science Press, Beijing, China, 2001.

[11] D. Tonini, "Obseved behavior of several leakier arch dams," New York: Journal of the Power Division, vol. 82, pp. 115-123, 1956.

[12] P. Bonaldi, M. Fanelli, and G. Giuseppetti, "Displacement forecasting for concrete dams via deterministic mathematic models," Water Power \& Dam Construction, vol. 29, pp. 74-78, 1977.

[13] E. G. Gaziev, "Safety provision and an expert system for diagnosing and predicting dam behavior," Hydrotechnical Construction, vol. 34, no. 6, pp. 285-289, 2000.

[14] J. Mata, A. Tavares de Castro, and J. Sá da Costa, "Constructing statistical models for arch dam deformation," Structural Control and Health Monitoring, vol. 21, no. 3, pp. 423-427, 2014.

[15] C. Gu, Y. Wu, H. Su, and L. Tang, "A new method of estimating the equivalent elastic modulus of RCCD," Science China Technological Sciences, vol. 50, no. 1, pp. 136-143, 2007.

[16] C. S. Gu, Theories and methods of safety diagnosis and earlywarning for roller compacted concrete dams, Hohai University Press, Nanjing, China, 2013.

[17] K. T. Fang and C. X. Ma, Orthogonal and uniform test design, Science Press, Beijing, 2001.

[18] J. P. Zhang, Z. C. Lu, L. B. Li, C. Zhao, and S. M. Li, "Study on statistics model for analysis of frost heaving deformation of concrete dams," Dam Safety, vol. 4, pp. 28-32, 2007.

[19] H. Su, Z. Wen, X. Sun, and M. Yang, "Time-varying identification model for dam behavior considering structural reinforcement," Structural Safety, vol. 57, pp. 1-7, 2015.

[20] E. T. Jaynes, "Information theory and statistical mechanics," Physical Review A: Atomic, Molecular and Optical Physics, vol. 106, no. 4, pp. 620-630, 1957.

[21] Z. Y. Wan, Investigation on deformation monitoring index of a roller compacted concrete gravity dam in an alpine region during operation period [M.S. thesis], China Three Gorges University, 2017. 


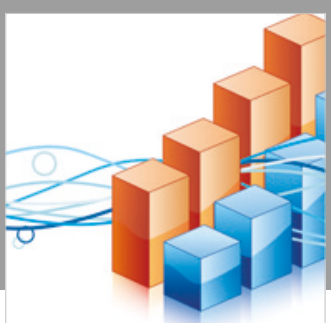

Advances in

Operations Research

\section{-n-m}
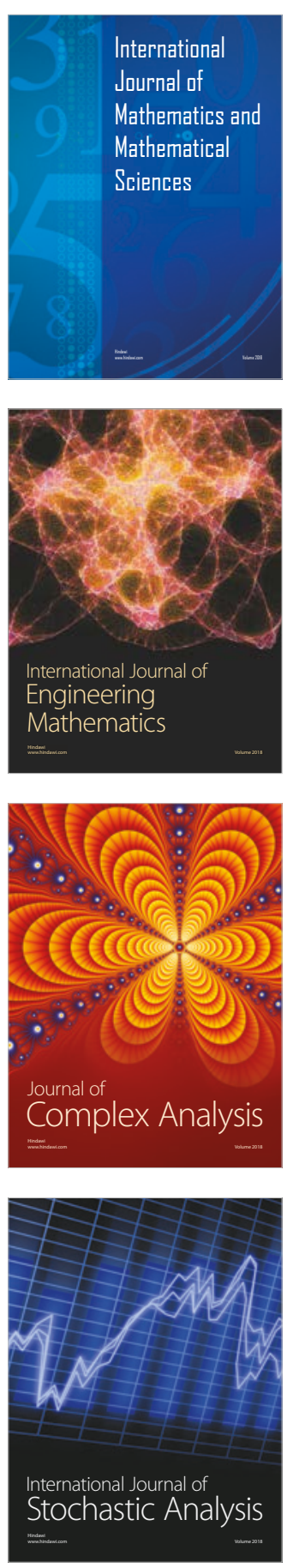
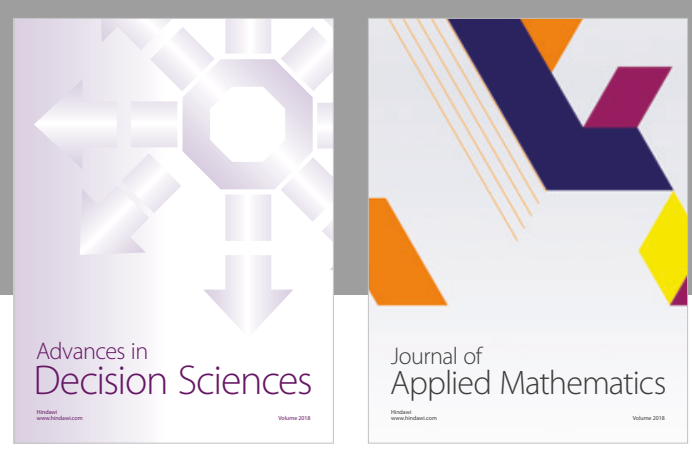

Journal of

Applied Mathematics
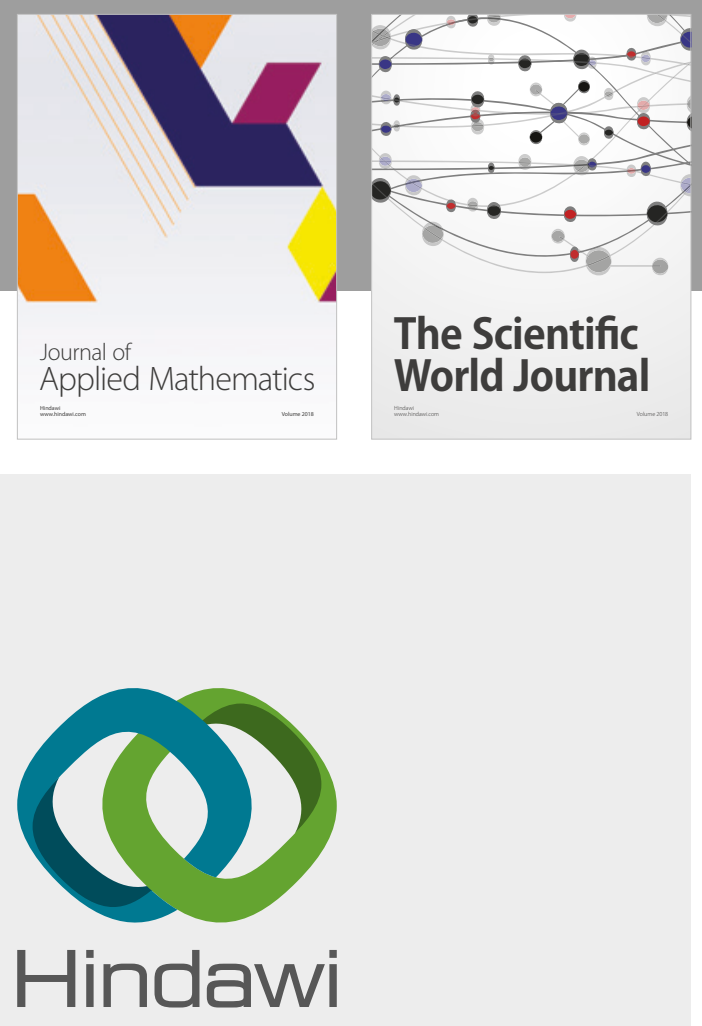

Submit your manuscripts at

www.hindawi.com

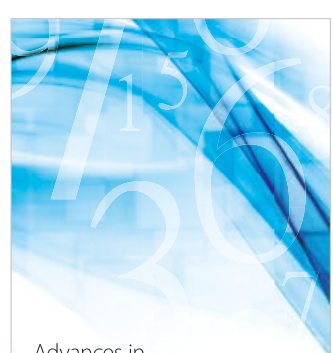

Advances in
Numerical Analysis
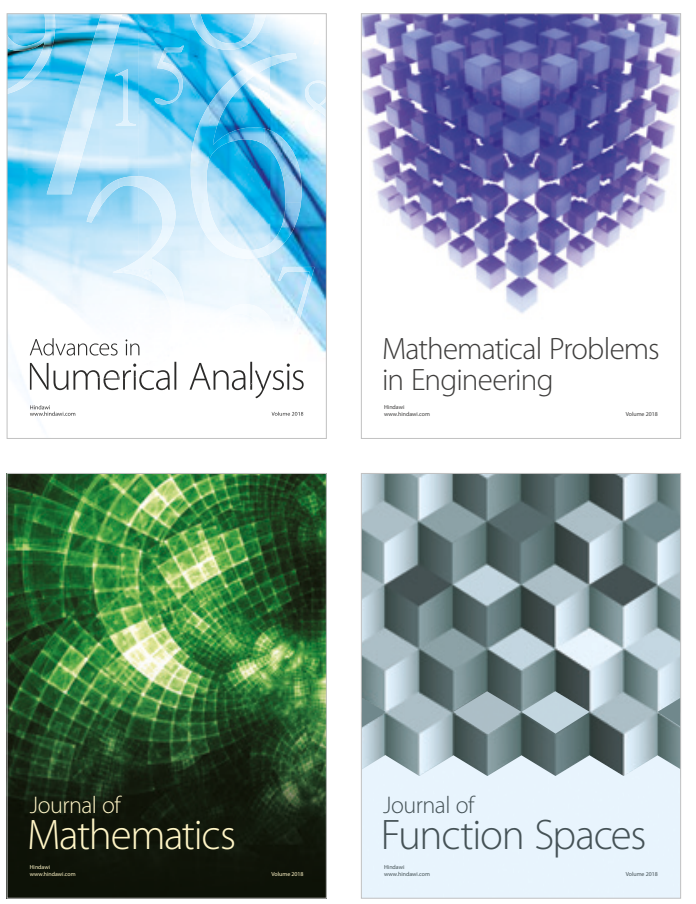

Mathematical Problems in Engineering

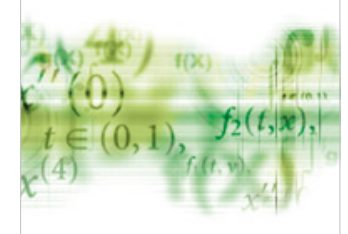

International Journal of

Differential Equations

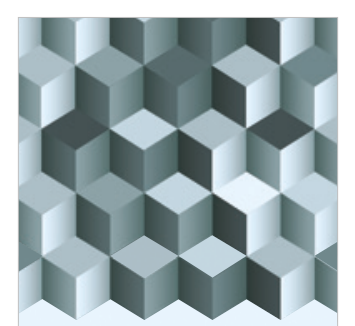

Journal of

Function Spaces

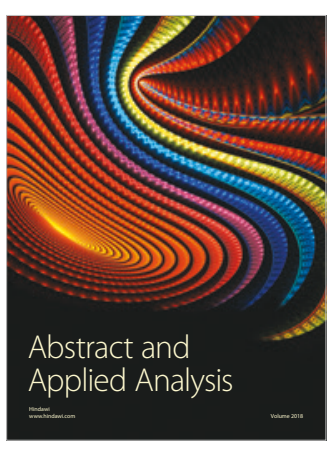

The Scientific

World Journal

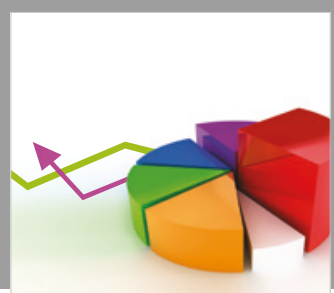

Journal of

Probability and Statistics
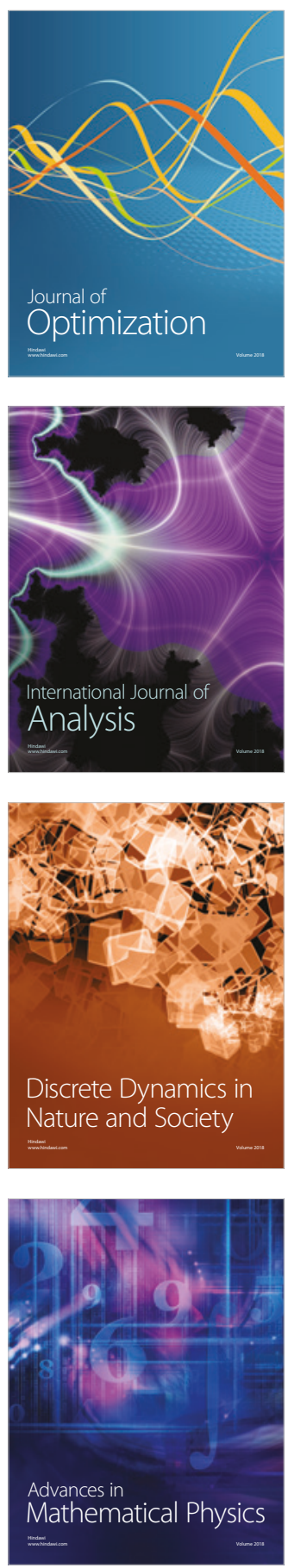